\title{
Influência do Ambiente Domiciliar no Desenvolvimento Motor de Lactentes Nascidos Pré-Termo
}

\author{
Motor Development Home Environment Influence of Premature Infants \\ Elaine Alegre Bueno ${ }^{1}$, Antônio Adolfo Mattos de Castro², \\ Eloá Maria dos Santos Chiquetti ${ }^{3}$
}

\begin{abstract}
RESUMO
A prematuridade é apontada como fator de risco biológico para o desenvolvimento típico motor. Sendo o desenvolvimento motor, multifatorial, crianças prematuras são mais vulneráveis a atrasos e sequelas no processo de desenvolvimento devido à imaturidade dos órgãos e sistemas ao nascimento, necessitando atenção especial. Objetivo. Verificar a influência do ambiente domiciliar no desenvolvimento motor de lactentes nascidos pré-termo. Método. Trata-se de um estudo descritivo com abordagem analítica e quantitativa, realizado com 21 lactentes pré-termos. Para avaliar o desenvolvimento motor foi utilizada a escala Alberta Infant Motor Scale (AIMS), para as oportunidades ambientais a AHEMD-IS Affordances in the Home Environment for Motor Development Infant-Scale. Resultados. Mostraram que 61,9\% dos lactentes apresentaram desenvolvimento motor alterado (suspeita de atraso e atraso). A comparação entre as variáveis AIMS e AHEMD-IS (escore total e dimensóes) apresentou diferença estatisticamente significante $(\mathrm{p}=0,02)$ na dimensão "brinquedos". Conclusáo. As condiçôes presentes no ambiente domiciliar da amostra não favorecem o desenvolvimento motor na maioria das residências estudadas. $\mathrm{O}$ estudo ratifica a tese de diversos autores de que o desenvolvimento motor é multifatorial, envolvendo características biológicas, fatores psicológicos, sociais e ambientais. Paralelamente aos fatores de risco biológicos, as desvantagens ambientais podem influenciar negativamente a evolução do desenvolvimento das crianças.
\end{abstract}

Unitermos. Prematuro, Desempenho Psicomotor, Lactentes, Fatores de Risco.

Citação. Bueno EA, Castro AAM, Chiquetti EMS. Influência do Ambiente Domiciliar no Desenvolvimento Motor de Lactentes Nascidos Pré-Termo.

\begin{abstract}
Infant's prematurity is a biological risk factor for typical motor development. Motor development being multifactorial, premature infants are more vulnerable to delays and sequelae in the development process due to the immaturity of organ systems at birth, requiring special attention. Objective. To assess the home environment influence of motor development in premature infants. Method. This is a descrpitive, analitical and quantitative study with 21 premature infants. In order to assess motor development the Alberta Infant Motor Scale (AIMS used; and to assess environmental opportunities the AHEMD-IS Affordances in the Home Environment for Motor Development InfantScale was used. Results. We showed that $61.9 \%$ of infants presented altered motor development (suspicious motor delay and delayed). We found a statistically significant difference between the AIMS and AHEMD-IS (total and dimensions) especially in the "toys" dimension $(\mathrm{p}=0.02)$. Conclusion. We show that the conditions present in the household of the sample does not favor the motor development in most of the homes studied. Our findings are in pace with most literature that confirms that motor development is multifactorial evolving not only biological characteristics but also, psychological, social and environmental factors. Also and in accordance to this environmental disadvantages may negatively influence in infants motor development.
\end{abstract}

Keywords. Premature infant, Psychomotor Performance, Infants, Risk Factors.

Citation. Bueno EA, Castro AAM, Chiquetti EMS. Motor Development Home Environment Influence of Premature Infants.
Trabalho realizado na Universidade Federal do Pampa - UNIPAMPA, Uruguaiana-RS, Brasil.

1.Graduanda em Fisioterapia pela Universidade Federal do Pampa, Uruguaiana, RS, Brasil.

2.Fisioterapeuta, Doutor em Pneumologia, Docente do Curso de Fisioterapia da Universidade Federal do Pampa, Uruguaiana, RS, Brasil.

3.Fisioterapeuta, Mestre em Fisiologia do Exercício, Docente do Curso de Fisioterapia da Universidade Federal do Pampa, Uruguaiana, RS, Brasil.
Endereço para correspondência: Eloá MS Chiquetti E-mail: eloachiquetti@unipampa.edu.br 


\section{INTRODUÇÃO}

A Organização Mundial da Saúde divulgou que anualmente cerca de 15 milhóes dos nascidos mundialmente são pré-termos. $\mathrm{O}$ Brasil atinge a $10^{\mathrm{a}}$ posição com 279,3 mil partos de prematuros por ano ${ }^{1,2}$. A prematuridade é apontada como fator de risco biológico para o desenvolvimento típico motor ${ }^{1,3}$. As crianças apresentam no seu primeiro ano de vida, importantes aquisiçôes de habilidades motoras. Essas habilidades aumentam juntamente com o avançar da idade, de forma progressiva, facilitando a interação e exploração da criança em seu ambiente conforme sua evolução $0^{4,5}$.

Sendo o desenvolvimento motor, multifatorial, crianças prematuras são mais vulneráveis a atrasos e sequelas no processo de desenvolvimento devido à imaturidade dos órgãos e sistemas ao nascimento, necessitando atenção especial ${ }^{5-8}$. Além dos riscos biológicos para o desenvolvimento faz-se necessário analisar os riscos ambientais, principalmente o familiar (condições de saúde, recursos sociais e de educação além das práticas de cuidado), já que o desenvolvimento motor é produto da interação entre fatores biológicos, psicológicos e sociais ${ }^{1,3,8-11}$.

Levando em consideração a falta de conhecimento por parte das mães acerca do processo de evolução infantil, é de suma importância que profissionais da saúde ${ }^{12}$, entre eles o fisioterapeuta ${ }^{5}$, desenvolvam trabalhos que contribuam para o melhor entendimento dos fatores de risco para o desenvolvimento infantil, pois nessa fase, os estímulos são de altíssima significância, mais do que em qualquer outro período da vida, visto que, do ponto de vista sensório-motor, neste período o Sistema Nervoso Central está em processo de maturação, e qualquer alteração terá como consequência o prejuízo ao processo de crescimento, uma vez que a falta de experiência e estímulos na infância geram morbidade, pois interfere no controle motor, causando dependência funcional na vida futura das crianças ${ }^{3,7,9}$.

Sendo assim, este trabalho teve como objetivo verificar a influência do ambiente no desenvolvimento motor de lactentes nascidos pré-termo.

\section{MÉTODO}

\section{Amostra}

Trata-se de um estudo descritivo com abordagem analítica e quantitativa, realizado com 21 lactentes pré-termos, levantando questóes acerca do tema e analisando as características apresentadas em um dado momento, produzindo medida de prevalência sem que haja ideia de tempo. Os critérios de inclusão foram: crianças com idade corrigida de três a 18 meses nascidas pré-termo. Foram adotados como critérios de exclusão crianças que apresentavam histórico de internaçóes hospitalares recorrentes, síndromes congênitas, patologias neurológicas e/ ou problemas ortopédicos.

Este trabalho seguiu as normas da resolução $\mathrm{n}^{\circ}$. 196/96 do Conselho Nacional de Saúde, com parecer do Comitê de Ética em Pesquisa da Universidade Federal do Pampa, aprovado sob o número 218.522. O consentimento em participar da pesquisa se deu através da leitura e assinatura do Termo de Consentimento Livre e Esclarecido pela responsável antes da realização dos procedimentos.

\section{Instrumentos}

Os dados foram coletados por uma única pesquisadora. Foram utilizadas duas ferramentas de avaliação. Para avaliar o desenvolvimento motor foi utilizada a $\mathrm{Al}$ berta Infant Motor Scale (AIMS) ${ }^{4,5}$, uma escala padronizada confiável desenvolvida por Piper \& Darrah $^{13}$ e validada para a população brasileira ${ }^{14}$. A ferramenta avalia o desenvolvimento motor de bebês do nascimento até o caminhar independente, inclui 58 critérios motores, distribuídos em quatro sub escalas descrevendo três aspectos do desempenho motor (sustentação de peso, postura e movimentos antigravitacionais), nas posturas: prono (21 itens), supino (9 itens), sentada (12 itens) e em pé (16 itens). Para cada item observado um ponto é marcado na escala; cada item não observado recebe escore zero. Ao final da avaliação o escore bruto é obtido a partir da soma do escore em cada uma das subescalas, convertido em percentil. Os percentis permitem determinar o desempenho motor do bebê, categorizado de acordo com os seguintes critérios: a) desempenho motor normal/esperado quando o resultado do teste for acima de $25 \%$ da curva percentílica; b) desempenho motor suspeito, quando o resultado for de $25 \%$ e $6 \%$ da curva percentílica; c) desempenho motor anormal, quando o resultado for menor ou igual a $5 \%$ da curva percentílica. É importante 
salientar que a AIMS é utilizada na avaliação de zero até 18 meses de idade e só tem validade na identificação do atraso motor no momento em que é utilizada, não diagnosticando atrasos futuros ${ }^{14}$.

Para avaliar a presença de oportunidades no ambiente domiciliar, foi empregado como instrumento o questionário Affordances in the Home Environment for Motor Development Infant-Scale (AHEMD-IS), que avalia crianças de três a 18 meses de idade, criado no Instituto Politécnico de Viana do Castelo, em Portugal, juntamente com o Laboratório de Desenvolvimento Motor da Texas (A\&M University, EUA) com apoio do Laboratório de Pesquisa em Desenvolvimento Neuromotor da Universidade Metodista de Piracicaba, encontra-se em processo final de validaçáo no Brasil, para permitir uma melhor adequação ao nosso perfil infantil ${ }^{10,11,15}$.

O questionário possui três dimensões: espaço físico, atividades diárias e brinquedos, com um total de 48 questóes. $\mathrm{O}$ escore é calculado pela soma dos pontos obtidos para todas as questôes dentro de cada dimensão. A pontuação total do instrumento é obtida pelo somatório das três dimensôes. Tal escore foi dividido com base nos índices tercis encontrados na amostra e classificados em "baixa (10 tercil)", "média (2o tercil)" e "alta (3o tercil)" oportunidade. $\mathrm{O}$ escore total do AHEMD-IS foi calculado para dois grupos: três a nove meses e dez a 18 meses, uma vez que as habilidades motoras e as oportunidades para o desenvolvimento motor presentes no domicílio são bastante heterogêneas nestas faixas etárias. Foi utilizado o seguinte critério de pontuação: para a faixa etária de 3 a 9 meses foi considerada classificação "Baixa Oportunidade" quando $\leq 37$ pontos, "Média Oportunidade" quando entre 38 e 49 pontos e "Alta Oportunidade" quando $\geq 50$ pontos; e para a idade de dez a 18 meses, "Baixa Oportunidade" quando $\leq 50$ pontos, "Média Oportunidade" quando entre 51 e 68 pontos e "Alta Oportunidade" quando $\geq 69$ pontos $^{14,15}$.

Para avaliação socioeconômica foi utilizado o critério ABEP, um instrumento de segmentação econômica, utilizando o levantamento das características domiciliares (presença e quantidade de alguns itens de conforto doméstico e grau de escolaridade do chefe da família) para identificar a condição socioeconômica da população ${ }^{1,16}$. Para obtenção dos dados pessoais, foi adotado um ques- tionário com perguntas sobre idade, gestaçôes, ordem de filiação, ocupação, se desejou a gravidez, se realizou prénatal e número de filhos.

Para a coleta de imagens foi utilizada uma câmera filmadora (Panasonic-Lumix 5MP DMC-LZ3LB-S) acoplada a um tripé.

\section{Procedimentos}

Todas as crianças nascidas no município são encaminhadas para a puericultura na Policlínica Infantil da cidade, nesta ocasião são cadastradas em um banco de dados. Neste cadastro selecionamos lactentes pré-termos nascidos no período de janeiro/2012 a abril/2013, e via contato telefônico foi marcada uma entrevista em suas respectivas residências, por ser o âmbito doméstico um requisito mais fidedigno para obtenção dos dados.

Os procedimentos consistiram na explicação do estudo às mães, seguida da entrevista para coleta de dados e preenchimento dos questionários ABEP e AHEMD-IS, pela própria mãe da criança, sem considerar passeios realizados pela família em parques ou outros ambientes fora de casa, bem como a presença de outras crianças que não fossem moradoras do mesmo domicílio.

A avaliação foi realizada através de filmagem das crianças, todas dentro de suas moradias, geralmente na sala, onde ficavam à vontade sobre um tapete no chão. Os bebês foram colocados nas posições prono, supino, sentado e em pé, com o mínimo de manipulação, porém com o intuito de despertar interesse das crianças e estimular a livre movimentação, as mães eram orientadas a chamar seus filhos ou thes ofertar brinquedos. A filmadora foi posicionada de forma a capturar imagens da criança nas posturas necessárias para avaliação com a AIMS. As mães estiveram presentes em todo momento da avaliação, sendo que o tempo não excedeu 20 minutos. Para evitar estresse da criança, caso estivesse chorosa, a filmagem era combinada para o dia seguinte. Todas as coletas ocorreram no verão, de forma que as crianças permaneceram com o mínimo de roupas e sem desconforto físico.

\section{Análise dos Dados}

A análise estatística foi realizada de forma descritiva onde foram calculados a média, desvio padrão e frequências absoluta e relativa das variáveis coletadas. Para ana- 
lisar a relação entre o desenvolvimento motor normal ou alterado com as variáveis como o número de filhos, presença do pai, desejo da gestação materna, ocupação e escolaridade materna, situação socioeconômica e se o lactente frequentou creches, foi utilizado o teste exato de Fisher.

O teste do qui-quadrado foi utilizado para analisar a proporção de crianças com desenvolvimento motor normal e alterado avaliado pela AIMS em relaçâo à alta, média e baixa oportunidade nos domínios espaço físico, atividades diárias, brinquedos e escore total do AHEMD IS. Foram fixados valores de confiança de 5\% $(p<0,05)$ considerados como estatisticamente significante. Para a análise estatística foi utilizado o software SPSS versão15.0.

O cálculo da amostra foi realizado por meio da equação $\mathrm{E} / \mathrm{S}$, na qual $\mathrm{E}=$ a diferença clinicamente significativa da variável desfecho e $S$ = corresponde ao desvio padrão da amostra da mesma variável. Considerando $25 \%$ de variação da pontuação da Escala de Avaliação Alberta Infant Motor Scale e considerando um $\alpha=0,05$ e $\beta=0,2$, foram necessários 21 sujeitos para dar poder a amostra.

\section{RESULTADOS}

Participaram do estudo 21 lactentes, sendo 11 $(52,38 \%)$ meninos e $10(47,62 \%)$ meninas, com a média da idade corrigida de 9₫3,66 meses. Nesta amostra havia três pares de gêmeos, totalizando assim 18 mães. A maioria era filho único (42,84\%), enquanto que $28,56 \%$ possuíam um irmão e outros $28,56 \%$ tinham três ou mais irmãos; $14,28 \%$ não contavam com a presença paterna. Apenas uma mãe $(5,55 \%)$ não fez pré-natal. Ao serem questionadas quanto ao planejamento da gravidez $38,08 \%$ das mães relataram não ter desejado a gravidez. As demais características (variáveis maternas e características da amostra) estão apresentadas na Tabela 1.

Ao nascerem, 12 lactentes necessitaram de cuidados em Unidade de Terapia Intensiva (UTI), sendo as causas: baixo peso (3), cianose por circular de cordão (1), icterícia (3), anemia (1), crise de abstinência por drogadição materna (1), para adquirir maturação pulmonar (3). Nenhuma das mães relatou ter recebido orientaçôes sobre como estimular adequadamente seu filho ou fazer parte de algum programa de follow up.
Tabela 1

Distribuição de frequência das características descritivas da população estudada (bebês $n=21$; mães $n=18$ ) - variáveis categóricas

\begin{tabular}{|c|c|}
\hline Variáveis Maternas & $f(\%)$ \\
\hline \multicolumn{2}{|l|}{ Idade (anos) } \\
\hline 15 a 19 & $4(22,2)$ \\
\hline 20 a 35 & $8(44,5)$ \\
\hline 36 a 50 & $6(33,3)$ \\
\hline \multicolumn{2}{|l|}{ Ecolaridade } \\
\hline Ensino Fundamental & $8(44,4)$ \\
\hline Ensino Médio & $9(50)$ \\
\hline Ensino Superior & $1(5,6)$ \\
\hline \multicolumn{2}{|l|}{ Condição Socioeconômica } \\
\hline B1/B2 & $3(16,6)$ \\
\hline $\mathrm{C} 1 / \mathrm{C} 2$ & $11(61,2)$ \\
\hline D & $4(22,2)$ \\
\hline \multicolumn{2}{|l|}{ Variáveis dos Bebês } \\
\hline \multicolumn{2}{|l|}{ Sexo } \\
\hline Feminino & $10(47,6)$ \\
\hline Masculino & $11(52,36)$ \\
\hline \multicolumn{2}{|l|}{ Internaçáo em UTI } \\
\hline Sim & $12(57,14)$ \\
\hline \multirow[t]{2}{*}{ Náo } & $9(42,86)$ \\
\hline & Média $\pm D P$ \\
\hline Idade Gestacional (semanas) & $34,85 \pm 1,71$ \\
\hline Idade Cronológica (meses) & $10,28 \pm 3,74$ \\
\hline Idade Corrigida (meses) & $9 \pm 3,66$ \\
\hline Peso ao Nascer (gramas) & $2.425 \pm 428,86$ \\
\hline Perímetro Cefálico $(\mathrm{cm})$ & $32,23 \pm 1,78$ \\
\hline
\end{tabular}

Dados apresentados como média \pm desvio padrão ou como frequência absoluta

Considerando a idade corrigida para cálculo dos escores percentílicos da AIMS, dos 21 lactentes avaliados, 61,9\% apresentou desenvolvimento motor alterado (suspeito e atraso). Os escores do desenvolvimento motor da amostra estão apresentados no Gráfico 1.

A maioria dos lactentes permaneceu sob os cuidados da mãe, sendo que apenas $9,52 \%$ da amostra frequentaram creche pelo menos por seis meses, estando essas dentro dos lactentes que obtiveram um desempenho superior na escala do desenvolvimento da AIMS. A análise estatística de proporçôes entre as variáveis de desenvolvimento motor normal e alterado com relação ao número de filhos, presença do pai, desejo da gestação, ocupação e escolaridade materna, situação socioeconômica e se o 


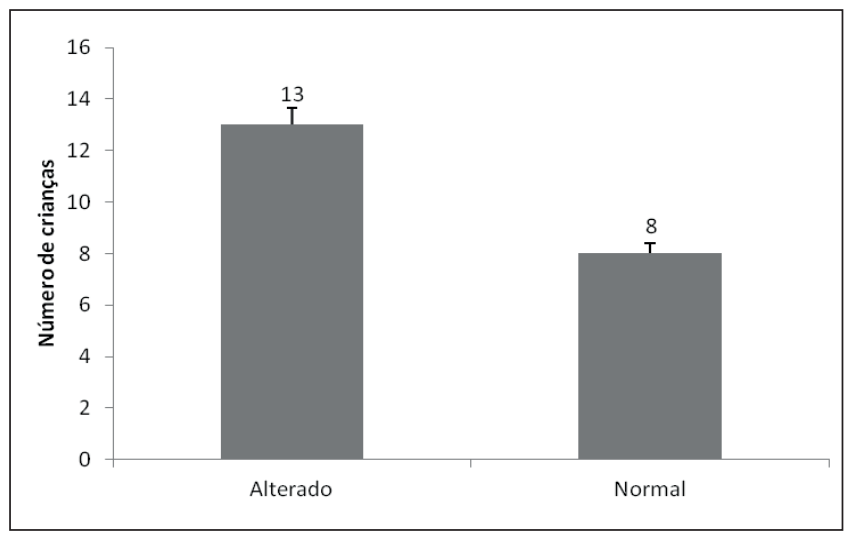

Gráfico 1. Distribuição da amostra segundo a classificação da AIMS $(\mathrm{n}=21)$.

lactente frequentou creches, não apresentou resultado estatisticamente significativo. Os valores das variáveis em relação ao desenvolvimento motor com atraso e normal estão descritos na Tabela 2.

A análise da proporção do desenvolvimento motor avaliados pelas variáveis das escalas de AIMS e AHEMD-IS (escore total e dimensóes) apresentou diferença $(\mathrm{p}=0,02)$ da dimensão "Brinquedos", onde os lactentes com desenvolvimento alterado pertenciam tanto às categorias "Muito Fraco e Fraco" quanto à "Bom e Muito Bom" de estímulos com brinquedos. Na Tabela 3, estão descritos os dados encontrados com o cruzamento dos dados das ferramentas AIMS e AHEMD-IS.

\section{DISCUSSÃO}

Este estudo apresentou como objetivo verificar o desenvolvimento motor de lactentes prematuros de três a 18 meses e as oportunidades de estimulação ambiental presentes no contexto domiciliar. Considerando que o desenvolvimento motor é decorrente da interação de vários fatores, sendo necessário além de diversas estimulaçôes, um ambiente domiciliar adequado pelo menos durante os primeiros anos de vida, o domicílio é um agente primordial para o aprendizado e desenvolvimento, o que tem levado pesquisadores a investigar relaçóes entre o ambiente e aspectos do desenvolvimento da criança ${ }^{1,8-11,17-22}$.

Verifica-se nesse trabalho que grande parte da amostra era de filho único, nas residências onde não houve a presença de outras crianças acredita-se terem oferecido poucos estímulos sociais e modelos motores para que os pré-termos se desenvolvessem, sendo ofertadas menos oportunidades de observar e reproduzir atividades que os lactentes com maior idade realizam. É citado em um estu$\mathrm{do}^{23}$, que lares de filhos únicos, favorecem o atraso motor. Essa condição é contrária ao achado em outro trabalho", que, por sua vez, aponta que são as famílias com vários filhos que contribuem para o atraso motor, pois nesse caso a mãe teria pouco tempo disponível para estimular os filhos. Quanto à presença de um companheiro, estudos demonstraram ${ }^{15,24}$ que mulheres casadas ou que possuem união conjugal estável, têm mais chances de oferecer alta oportunidade para o desenvolvimento motor; a presença da figura paterna interfere positivamente na qualidade da estimulação disponível no ambiente familiar; acredita-se que a presença do pai ou um chefe de família, fornecendo apoio, tenha contribuído para um desenvolvimento motor adequado em parte da população estudada.

Tabela 2

Análise da proporção de crianças com desenvolvimento motor normal e alterado em relaçâa ao número de filhos, a presença do pai, ao desejo da gestação materna, a ocupação e instrução da mãe, a situação socioeconômica e se freqüentou creches

\begin{tabular}{|c|c|c|c|}
\hline \multirow{2}{*}{ Variáveis } & \multicolumn{2}{|c|}{ Desenvolvimento motor - AIMS } & \multirow{2}{*}{$p$} \\
\hline & Normal & Alterado & \\
\hline Presença de filho único, $n(\%)$ & $8(38,09)$ & $13(61,90)$ & 0,6 \\
\hline Presença do pai, n(\%) & $18(85,71)$ & $3(14,28)$ & 0,6 \\
\hline Desejo materno à gestaçáo, n(\%) & $12(66,66)$ & $6(33,33)$ & 0,4 \\
\hline Ocupação da mãe, n(\%) & $1(5,55)$ & $17(94,44)$ & 0,4 \\
\hline Instruçáo da máe, n(\%) & $8(44,44)$ & $10(55,55)$ & 1,0 \\
\hline Situaçáo socioeconômica, n(\%) & $4(22,22)$ & $16(88,22)$ & 1,0 \\
\hline Criança que frequentou creches, $n(\%)$ & $2(9,52)$ & $19(90,47)$ & 0,2 \\
\hline
\end{tabular}


Tabela 3

Comparação da proporção de repostas do desenvolvimento motor normal e alterado da AIMS e quanto ao escore total do AHEMD-IS, ao espaço físico, atividades diárias e brinquedos em 21 crianças pré termos

\begin{tabular}{|c|c|c|c|c|c|}
\hline \multicolumn{6}{|c|}{ Desenvolvimento Motor-AIMS } \\
\hline \multirow{4}{*}{$\begin{array}{c}\text { AHEMD-IS } \\
\text { Total }\end{array}$} & & $\begin{array}{l}\text { Normal } \\
\mathrm{f}(\%)\end{array}$ & $\begin{array}{c}\text { Alterado } \\
\mathrm{f}(\%)\end{array}$ & Total & $P$ \\
\hline & $\begin{array}{c}\text { Baixa } \\
\text { Oportunidade }\end{array}$ & $1(4,76)$ & $5(23,80)$ & $6(28,57)$ & \multirow{3}{*}{0,07} \\
\hline & $\begin{array}{c}\text { Média } \\
\text { Oportunidade }\end{array}$ & $8(38,09)$ & $3(14,28)$ & $11(52,80)$ & \\
\hline & $\begin{array}{c}\text { Alta } \\
\text { Oportunidade }\end{array}$ & $3(14,28)$ & $1(4,76)$ & $4(19,04)$ & \\
\hline \multirow[b]{2}{*}{ Espaço Físico } & $\begin{array}{c}\text { Muito Fraco } \\
\text { e Fraco }\end{array}$ & $4(19,04)$ & $5(23,80)$ & $9(42,85)$ & \multirow[b]{2}{*}{0,38} \\
\hline & $\begin{array}{c}\text { Bom e } \\
\text { Muito Bom }\end{array}$ & $8(38,09)$ & $4(19,04)$ & $12(57,14)$ & \\
\hline \multirow{2}{*}{$\begin{array}{l}\text { Atividades } \\
\text { Diárias }\end{array}$} & $\begin{array}{l}\text { Muito Fraco } \\
\text { e Fraco }\end{array}$ & $0(0)$ & $1(4,76)$ & $1(4,76)$ & \multirow[b]{2}{*}{0,93} \\
\hline & $\begin{array}{c}\text { Bom e } \\
\text { Muito Bom }\end{array}$ & $12(57,14)$ & $8(38,09)$ & $20(95,23)$ & \\
\hline \multirow[b]{2}{*}{ Brinquedos } & $\begin{array}{c}\text { Muito Fraco e } \\
\text { Fraco }\end{array}$ & $1(4,76)$ & $3(14,28)$ & $4(19,04)$ & \multirow[b]{2}{*}{$0,02^{*}$} \\
\hline & $\begin{array}{c}\text { Bom e } \\
\text { Muito Bom }\end{array}$ & $11(52,80)$ & $6(28,57)$ & $17(80,95)$ & \\
\hline
\end{tabular}

Dados apresentados como frequência absoluta (frequência relativa).

*Nível de significância $p \leq 0,05$

Outra questão que pode ter relação com o atraso das crianças é o fato de parte das mães não ter desejado a gravidez, o que nos remete a pensar que tendo desejado a gestação, a mãe poderia ter maior motivação para estimular sua criança. É apontada na literatura, como consequência da gravidez não desejada, a prematuridade ${ }^{7}$, dessa forma ocorre uma percepção distorcida dos pais em relação ao filho pré-termo, sua condição de "fragilidade" leva-os a interagem menos com seu filho ${ }^{1,7}$. Sendo assim, a condição de não ter desejado a gravidez, pode ter levado algumas mães a manter desinteresse em suas práticas maternas.

Um achado relevante é que 90,44\% da amostra de crianças permaneciam constantemente sob os cuidados maternos, comprovando que as mães não possuíam ocupação. A literatura sugere que mães que trabalham possuem percepçóes mais otimistas em relação aos filhos, oferecendo um ambiente mais seguro e estimulante para estes, favorecendo inclusive o desenvolvimento cognitivo $^{24,25}$, possivelmente a falta de uma atividade laboral pode ter contribuído para os atrasos encontrados em nossa amostra. Essa questão tem relação com a condição econômica familiar, uma vez que a renda é determinante para a qualidade de vida das famílias ${ }^{1,8,19,26}$. Ao que tudo indica, a condição econômica da família influencia significativamente o ambiente físico da criança, pois crianças criadas na pobreza apresentam menor possibilidade de receber brinquedos adequados, material didático e espaço pessoal em relação àquelas criadas em melhores condiçóes de vida, ao receber menos estímulos houve como consequência atraso no desenvolvimento $8,11,15,23,26$. Pode ser que a condição financeira do grupo estudado possa ter interferido em parte, no desenvolvimento das crianças, devido limitações causadas pela baixa renda familiar.

Outra condição apontada na literatura que constitui risco para o desenvolvimento de prematuros é o grau de escolaridade materna ${ }^{3,6,8,11,26}$. Trabalhos publicados recentemente ${ }^{23,27}$ apontam que na primeira infância a criança é mais vulnerável, sendo suscetível aos riscos ambientais. A baixa escolaridade age indiretamente sobre a capacidade 
da mãe de cuidar adequadamente de seu filho, na medida em que o acesso às informaçóes veiculadas pelos serviços de saúde, educação, mídia e a compreensão delas são reduzidas $^{8,23,27}$. Lactentes de mães com níveis de escolaridade reduzidos, e estâo inseridos em um ambiente com poucas oportunidades de estimulação, possuem maior probabilidade de apresentarem baixo desempenho na AIMS ${ }^{23,28}$. Os achados desse trabalho revelam o contrário, já que as mães deste estudo relataram ter escolaridade de oito anos ou mais. Autores demonstram que mães com maior nível de instrução parecem possuir maior entendimento sobre o desenvolvimento infantil e interagem melhor com seus filhos, respondendo adequadamente às suas solicitaçóes e fornecendo melhores condiçôes estruturais e emocionais para o adequado desenvolvimento motor ${ }^{6,8,15,28}$.

Este estudo aponta que os lactentes que obtiveram maiores escores no desenvolvimento motor de acordo com a AIMS, foram aqueles que frequentaram creches, sugerindo que o estímulo ofertado neste ambiente, forneceu aos pré-termos melhores oportunidades. A literatura sugere ${ }^{22}$, que mesmo que as crianças possuam poucas oportunidades de estimulação em suas residências, ao frequentarem uma creche, são influenciadas positivamente no desenvolvimento motor, possuindo maior exposição de diferentes situações físicas e sociais. Possivelmente, o estímulo recebido nas creches foi mais pontual que a condição econômica, já que a quantidade e variedade de brinquedos presentes não contribuíram para um bom desenvolvimento motor de alguns lactentes, uma vez que os resultados das dimensões da AHEMD-IS não apresentam variáveis independentes entre si. Uma boa pontuação em apenas um domínio não significa que há um bom desenvolvimento, é necessário integração dos três domínios para caracterizar oferta de oportunidades adequadas.

Os resultados não indicaram que houve associação estatisticamente significativa entre o escore total do AHEMD-IS com o desempenho motor na AIMS. Trabalhos na área do desenvolvimento motor encontraram resultados similares ${ }^{15,26,28}$. Quanto aos escores do AHEMD-IS, a pontuação geral foi baixa, não sendo atingido nenhum terço do total da escala. É discutido em um trabalho ${ }^{28}$, que esses valores servem de indicadores de que não há oportunidades suficientes nos lares de lactentes, remetendo a uma oferta pobre de estímulos.
Consideramos que, independente da condição econômica da família, as oportunidades oferecidas no ambiente domiciliar não influenciaram no desenvolvimento de forma positiva nesse caso. Resultados semelhantes foram encontrados em outro estudo ${ }^{25}$. Esse dado corrobora com nossa pesquisa, onde $90,44 \%$ dos lactentes não puderam contar com a interferência de um ambiente rico de estímulos que favoreça ao desenvolvimento, podendo este fato ter contribuído no atraso detectado em parte da amostra.

\section{CONCLUSÃO}

A estimulação proporcionada às crianças no ambiente domiciliar é importante na modelação do desenvolvimento motor ${ }^{8,11}$, os espaços existentes na casa, os tipos de revestimentos dos solos (texturas), a existência de escadas e desníveis, temperatura, assim como a presença e a variedade de brinquedos demonstraram ser uma condição ambiental estimuladora do desenvolvimento das habilidades motoras infantis ${ }^{26}$. Foi evidenciado que as condiçóes presentes no ambiente domiciliar da amostra não favorece o desenvolvimento motor na maioria das residências estudadas. Os achados desse estudo ratificam a tese de diversos autores ${ }^{1,3,8-10,16-22}$ acerca de que o desenvolvimento motor é multifatorial, envolvendo além das características biológicas, fatores psicológicos, sociais e ambientais. Paralelamente aos fatores de risco biológicos, as desvantagens ambientais podem influenciar negativamente a evolução do desenvolvimento das crianças.

Um ponto importante que fica de sugestão para estudos futuros, é a respeito das orientaçóes acerca do desenvolvimento motor infantil recebido durante o pré-natal, podendo ter relaçáo com um melhor desempenho motor, uma vez que sendo orientada, a mãe é capaz de trabalhar melhores estímulos para seu filho.

Como contribuição, este estudo traz informações fundamentadas na literatura quanto ao desenvolvimento de prematuros e os dados da pesquisa contribuirão para aumentar o conhecimento científico dos fisioterapeutas e profissionais da saúde, servindo para auxiliar no desenvolvimento de programas que venham a trabalhar com intervençôes em lactentes pré-termo com atraso motor e dessa forma poderá auxiliar na promoção de açôes voltadas a estes, podendo ser um coadjuvante no direciona- 
mento das práticas maternas. Em suma, o conhecimento acerca dos fatores de riscos que podem levar ao atraso do desenvolvimento nas crianças é imprescindível, para implementar recursos que visem diminuir sua incidência, ou minimizar seus efeitos sobre a criança e a família.

\section{REFERÊNCIAS}

1.Mancini MC, Megale L, Brandão MB, Melo APP, Sampaio RF. Efeito moderador do risco social na relação entre risco biológico e desempenho funcional infantil. Rev Bras Saúde Matern Infant 2004;4:25-34.

http://dx.doi.org/10.1590/S1519-38292004000100003

2.Brasil - Ministério da Saúde - Datasus [Endereço na Internet]. Portal da Saúde - Ministério da Saúde - Saúde da Mulher - Rede cegonha busca reduzir índice de prematuros [atualizado em: 2012; citado em: 03/05/2012] Disponível Em: Http://Portalsaude.Saude.Gov.Br/Portalsaude/Noticia/4925/162/ Rede-Cegonha-Busca-Reduzir-Indice-De-Nascimentos-Prematuros.Html 3.Formiga CKMR. Programa de intervençấo com bebês pré-termo e suas famílias: avaliação e subsídios para prevenção de deficiências. [Dissertação de Mestrado] São Carlos: UFSCAR, 2003, 238p.

4.Venturella CB, Zanandrea G, Saccani R, Valentini NC. Desenvolvimento motor de crianças entre 0 e 18 meses de idade: Diferenças entre os sexos. J Motri 2013;9:3-12.

http://dx.doi.org/10.6063/motricidade.9(2).617

5.Willrich A, Azevedo CCF, Fernandes JO. Desenvolvimento motor na infância: influência dos fatores de risco e programas de intervenção. Rev Neurocienc 2009,17:51-6.

6.Fraga DA, Linhares MBM, Carvalho AEV, Martinez FE. Desenvolvimento de bebês prematuros relacionado a variáveis neonatais e maternas. PsicolEst2008; 13:335-44.

7.Campus RC. Processo gravídico, parto e prematuridade: Uma discussão teórica do ponto de vista do psicólogo. Anál Psicol 2000;1:15-35.

8.Rodrigues OMPR, Bolsoni-Silva AT. Efeitos da prematuridade sobre o desenvolvimento de lactentes. Rev Bras Cres Desenvolv Hum 2011;21:111-21.

9.Halpern R, Giuliani ERJ, Victoria CG, Barros FC, Horta BL. Fatores de risco para suspeita de atraso neuropsicomotor aos 12 meses de vida. J Ped 2002;76:421-8.

10.Rodrigues LP, Saraiva L, Gabbard C. Development and construct validation of na inventory for assessing the home environment for motor development. ResQuart Exe Sport 2005;76:140-8.

11.Batistela ACT. Relação entre as oportunidades motora no lar e o desempenho motor de lactentes - um estudo exploratório. [Dissertação de Mestrado]. Piracicaba: Unimep, 2010, 102p.

12.Rotta NT, Pedroso FS. Desenvolvimento neurológico: avaliação evolutiva. Rev AMRIGS 2004; 48:175-9.

13.Piper MC, Pinnell LE, Darrah J, Maguire T, Byrne PJ. Construction and validation of the Alberta Infant Motor Scale (AIMS). Can J Public Health 1991;83 (Suppl 2):S46-50.
14.Valentini, NC, Saccani, R. Escala Motora Infantil de Alberta: validação para uma população gaúcha. Rev Paul Pediatr 2011;29:231-8.

http://dx.doi.org/10.1590/S0103-05822011000200015

15.Defilipo EC, Frônio JS, Teixeira MTB, Leite ICG, Bastos RR, Vieira MT, et al. Oportunidades do ambiente domiciliar para o desenvolvimento motor. Rev Saúde Púb 2012; 46:633-41.

http://dx.doi.org/10.1590/S0034-89102012000400007

16.Corrêa CSL, de Oliveira DM. Oportunidades de estimulação motora presentes no domicílio de lactentes prematuros e/ou com baixo peso ao nascer. [Trabalho de Conclusão de Curso]. Juiz de Fora: Universidade Federal de Juiz de Fora 2011, 72p.

17.Sharma S, Nagar S. Influence of Home Environment on Psychomotor Development of Infants in Kangra District of Himachal Pradesh. J Soc Sci 2009;21: 225-9.

18.Miquelote AF, Santos DCC, Caçola PM, Montebelo MIL, Gabbard C. Effect of the home environment on motor and cognitive behavior of infants. Inf Beh Develop 2012;35:329-34.

http://dx.doi.org/10.1016/j.infbeh.2012.02.002

19.Lima MC, Eickmann SH, Lima ACV, Guerra MQ, Lira PIC, Huttly SRA, Ashworth A. Determinants of mental and motor development at 12 months in a low income population: a cohort study in northeast Brazil. Acta Paediatr 2004;93:969-75.

http://dx.doi.org/10.1111/j.1651-2227.2004.tb18257.x

20.Bradley R, Corwyn, R. Caring for children around the world: A view from HOME. Inter J Beh Develop2005;29:468-78.

http://dx.doi.org/10.1177/01650250500146925

http://dx.doi.org/10.1080/01650250500146925

21.Bradley RH, Caldwell BM, Rock SL, Ramey CT, Barnard KE, Gray C, et al. Home environment and cognitive development in the first 3 years of life: A collaborative study involving six sites and three ethnic groups in North America. Develop Psychol 1989;25:217-35.

http://dx.doi.org/10.1037/0012-1649.25.2.217

22.Moreira LVC, Lordelo ER. Creche em ambiente urbano: ressonâncias no ecossistema desenvolvimental. InterPsicol 2002;6:19-30.

23.Sinder CB, Ferreira MCP. Oportunidades do ambiente domiciliar e desenvolvimento motor de lactentes entre dez e 18 meses de idade. [Trabalho de Conclusão]. Juiz de Fora: Universidade Federal de Juiz de Fora , 2010, 3p. 24.Andrade AS, Santos DN, Bastos AC, Pedromônico MRM, Almeida Filho N, Barreto ML. Ambiente familiar e desenvolvimento cognitivo infantil: uma abordagem epidemiológica. Rev Saúde Púb2005;39:606-11.

http://dx.doi.org/10.1590/S0034-89102005000400014

25.Youngblut JM, Singer LT, Madigan EA, Swegart LA, Rodgers WL. Maternal employment and parent-child relationship in single-parent families of low-birth-weight preschoolers. Nurs Res1998;47:114-21.

http://dx.doi.org/10.1097/00006199-199803000-00010

26.Moreira MA, Santos DCC. Correlação entre as oportunidades de Estimulação motora no ambiente doméstico e a condição socioeconômica da família. 8a Mostra Acadêmica UNIMET, 2010, 4p.

27.Silva CR, Bolsanello MA. No cotidiano das creches o cuidar e o educar caminham juntos. Inter Psicol 2002;6:31-6.

28.Martins MFD, Costa JSD, Saforcada ET, Cunha MDD. Qualidade do ambiente e fatores associados: um estudo de crianças de Pelotas, Rio Grande do Sul, Brasil. Cad Saúde Púb2004;20:710-8.

http://dx.doi.org/10.1590/S0102-311X2004000300007 